\title{
Por Uma Cidade Aberta
}

\author{
Towards an Open City
}

\author{
> Rafael Lemieszek Pinheiro \\ Escola de Arquitetura da UFMG, Brasil \\ lemieszek@gmail.com
}

\begin{abstract}
Cities are seen as open platforms, in which citizens should be able to access information and propose, discuss and modify public policies without having to go through institutional and technocratic control. Systems based on collaborative platforms, such as Linux and Waze, are studied as experiences where user participation creates solutions that no centralized institutions are able to achieve, and looked at for references to build and manage platforms on which city planning could be based.
\end{abstract}

Keywords: Open Cities; Urban Planning; Collaborative Systems; Open Platforms; Participatory Processes

\section{Produção Espacial: Espontaneidade versus Prescrição}

"Cities have the capability of providing something for everybo$d y$, only because, and only when, they are created by everybody." (Jacobs, 1961)

Desde o início da vida em cidades até o fim do século XVIII nenhuma cidade no mundo havia excedido expressivamente a marca de um milhão de habitantes. A industrialização iniciou um processo de avanços científicos e tecnológicos que fizeram com que hoje, menos de dois séculos depois, existam mais de quatrocentas aglomeraçóes urbanas no mundo que passam desta marca (Demographia, 2013). Mais da metade da população mundial vive em cidades. $\mathrm{O}$ meio urbano é o caldo de cultura que produz virtualmente todo o conhecimento humano hoje. Cabe, entáo, a pergunta: quem faz as cidades?

$\mathrm{Na}$ arquitetura, Baltazar (2013) traz uma interessante história dos últimos séculos. Ela analisa o livro Hypnerotomachia Poliphili, de 1499 , que contrapóe o paradigma da vida ativa, em que "todos trabalham na produção do espaço, mas sem muita reflexão", ao da vida contemplativa, que representa "o trabalho intelectual do arquiteto e a realização dos desejos via intelecto". O Renascimento introduziu a atividade do arquiteto como algo intelectual, desenvolvido individualmente ou por um grupo muito restrito de pessoas. $\mathrm{O}$ desenho técnico passou a marcar uma separação entre a atividade intelectual, codificada em uma linguagem técnica acessível a um grupo restrito, e a atividade manual, executada por operários com conhecimento limitado e especializado. A produção arquitetônica ainda hoje segue o paradigma contemplativo: arquitetos costumam desenhar espaços com a intenção de prescrever detalhadamente seu uso, considerando o usuário como um ente passivo.

Há um embate entre a arquitetura produzida espontaneamente, na medida das necessidades e das possibilidades, e a arquitetura intelectualmente prescrita. René Descartes já trata do assunto em 1637: “... frequentemente não há tanta perfeição em obras compostas por várias peças, e produzidas pelas mãos de diversos mestres, quanto naquelas em que apenas um mestre tenha trabalhado. (...) $\dot{E}$ assim que essas cidades antigas que, tendo começado como pequenos vilarejos, se tornaram com o tempo grandes cidades, são normalmente tão mal compassadas quando comparadas com as praças regulares que um engenheiro traça à sua fantasia em uma planicie..." (Descartes, 1967)

Descartes, em consonância com a era renascentista em que vive, exalta as virtudes do trabalho intelectual em substituição ao simples fazer casual, incidental e coletivo. Daí a ambiguidade: enquanto não se pode negar que o apuramento racional tenha impulsionado o desenvolvimento tecnológico até os dias de hoje, isto ocorreu ao custo do alijamento do cidadão comum da atividade de produçâo do próprio espaço. Se o conhecimento técnico avançado permitiu a adoção de soluçóes tecnicamente sofisticadas, o conhecimento prático e cotidiano foi sendo deixado de lado. Como na metáfora que Descartes usou para falar de método científico, a coerência e eficiência da produção intelectual dependia da limitação do número de pessoas envolvidas na atividade de concepçáo do espaço. 
Quem não é especializado na concepçáo espacial intelectual deve se contentar com vivenciar o espaço de forma passiva - ou transgredir essas prescrições por sua própria conta.

Apesar do advento da especialização técnica na produção espacial, o modo medieval de produção não deixou de existir. A existência de termos como "cidade formal" e "cidade informal" é bom testemunho do caráter incompleto tanto da abordagem estritamente prática quanto da abordagem tecnicista. Em um extremo, o espaço arquitetônico "formal", produzido intelectualmente, homogeneizado e seletivo quanto às demandas individuais. No outro, a cidade "informal", autoconstruída, que usa soluçóes criativas e adaptadas às demandas de cada lugar e população, mas que frequentemente ignora possibilidades tecnológicas sofisticadas para resolver problemas. $\mathrm{O}$ apuramento intelectual e a espontaneidade são, nestas condições, auto excludentes: o que é produzido de forma tecnicamente avançada não é produzido pelos usuários, e a autoconstrução, por mais criativa que seja, não é tecnicamente apurada.

Daí a defesa do "paradigma erótico" de Baltazar: a busca por "um espaço vivido, mas com uma complexidade de concepçáo impensável na vida ativa medieval, e para além do espaço concebido da vida contemplativa renascentista". Não é uma questáo de se avançar em complexidade na busca de uma arquitetura formalmente ideal, como alguns modernistas tentaram fazer; mas também não há justificativa em se abandonar o apuramento tecnológico e voltar para o "paradigma ativo" da idade média. É o caso de empreender o caminho rumo a sistemas que permitam abrir o processo técnico de produção arquitetônica e permitir que qualquer pessoa interaja em algum nível com o processo de concepção e manejo do espaço.

Se na arquitetura o embate é legível, no urbanismo ele é inescapável. Nenhuma cidade, por sua extensão, complexidade e duração temporal, pode ser inteiramente concebida no campo intelectual para ser executada de forma definitiva.

\section{A superação do tecnicismo}

$\mathrm{O}$ alijamento do cidadáo comum da produção da cidade se intensificou depois da industrialização, a partir das demandas tecnológicas decorrentes das inéditas densidades populacionais. A rápida aglomeração de milhóes de pessoas em cidades no início do Século XIX, a começar por Londres e rapidamente acompanhada por cidades em todo o mundo, trouxe consequências igualmente rápidas. No livro The Ghost Map (2006), Steven Johnson descreve os surtos de cólera que dizimavam milhares de pessoas a cada ocorrência. $\mathrm{O}$ crescimento repentino da cidade náo foi acompanhado de adequada solução tecnológica para a disposição do esgoto, e o fenômeno demorou décadas para ser compreendido. Um médico, John Snow, se lançou a pesquisar estes surtos. Após anos de pesquisa suas teorias foram eventualmente aceitas, e em poucas décadas a cidade inteira estava servida de uma rede de esgoto que deu fim aos surtos. Este é um de vários exemplos que ilustram o papel que o conhecimento técnico especializado teve no desenvolvimento das megalópoles de hoje.

Mas o Século XX mostrou que o conhecimento técnico especializado não é capaz de encampar inteiramente a produção espacial. Quase toda cidade moderna tem exemplos: grandes obras que já se mostram obsoletas em sua inauguração; conjuntos habitacionais padronizados que começam a ser personalizados táo logo seja possível; e intervençóes em zonas socialmente fragilizadas, que gastam fortunas e acabam por quebrar a complexa fábrica social dessas áreas, descartando soluçóes criativas que as pessoas tenham desenvolvido sozinhas ao longo do tempo. O planejamento urbano tenta encontrar sistematizaçóes institucionais que promovam a qualidade de produção urbana, por meio da criação de leis e instituiçóes cada vez mais complexas, que têm progressivamente alijado o cidadão da produção espacial. Ainda que as soluções existam apenas embrionariamente, o diagnóstico já é visível, com a repetida declaração da necessidade de processos "participativos" de produção urbana. A ideia da criação de instituições e processos participativos se origina no diagnóstico correto de que o conhecimento técnico especializado não é capaz de produzir e gerenciar a cidade de forma adequada; trata-se, no entanto, de um conceito insuficiente e que deve ser superado, como veremos.

\section{A participação como um meio, não um fim}

A noção de que participação é um fenômeno fechado, limitado, e que se opóe à noção de centralização é um entrave para que se desenvolvam e amadureçam verdadeiras instituiçóes e processos colaborativos. Anuncia-se a participação como uma ação limitada, com começo, meio e fim, e sugere-se que as limitaçóes encontradas sejam inerentes ao processo, e não limitaçóes das decisóes próprias de cada processo adotado e que devem ser amadurecidas e aprimoradas. Supóe-se que o processo decisório técnico, tradicional, possa ser consertado apenas com a incorporação de um reduzido número de cidadáos, que se pretende que sejam representativos da população toda.

Participar efetivamente da vida em sociedade é muito mais complexo que isso. "Fazer parte", formalmente, não garante a autonomia das pessoas e das sociedades em que se inserem, como Kapp e Baltazar ilustram em The Paradox of Participation (2012). A autonomia de fato depende de uma capacidade de planejar o próprio espaço que náo consegue ser esgotada com processos objetivamente participativos.

Há pelo menos duas dimensões de atuação que devem ser conhecidas e tratadas conforme a instância em que se trabalha. Uma delas é a da forma de participação: da liberdade de expressar seus sentimentos à de propor, debater e influir sobre as soluçóes, passando pela reavaliação constante de diagnósticos, ideias e fatos, cada agente deve poder definir de que forma influirá nos rumos da sociedade em que se insere (em qualquer escala). A resposta centralizadora a isso é a ideia de que a participaçáo só pode ocorrer se todos - ou, pior, se uma parte aleatoriamente definida desse todo - se sentarem à mesa para debater no campo das ideias ou, se não quiserem ou não puderem, que aceitem tudo passivamente. Isso não é verdade, mas é frequentemente usado como obstáculo. A outra é o conhecimento técnico necessário para participar. Em vez de servir de barreira para isolar os agentes que influem nas políticas, elevando os detentores do conhecimento a pedestais inalcançáveis pelos agentes afetados, o conhecimento técnico deve existir em funçáo da sociedade, permanecendo como conceito do campo 
abstrato, ou seja: como "conhecimento técnico disponível", e não como "pessoa detentora do conhecimento técnico".

Esta visão binomial de participação pressupóe que os processos sejam exatamente os mesmos, mas com o convite a que os usuários, ou os agentes que normalmente são passivos no processo, sejam convidados à mesa com canetas na mão e façam parte do trabalho dos agentes centralizadores. Das duas, uma: ou o usuário se torna um agente dominante e é absorvido pelo processo, que segue tão restrito quanto antes, ou ele é incapaz de dialogar nos mesmos termos com o restante dos agentes dominantes e é mandado de volta para a massa dos afetados passivos.

Mas nem todos os processos serão absolutamente horizontais. O conhecimento técnico ainda é importante, mas não pode ser tratado como ferramenta excludente; deve, ao contrário, servir de base para plataformas de interface que permitam que cada agente se coloque em algum ponto na linha entre passividade total e controle total, conforme suas vontades, desejos e conhecimentos. Os extremos, correspondentes aos estados plenos da vida ativa e da vida contemplativa, ficarão, idealmente, vazios. Exprimir insatisfações e anseios, compartilhar e debater ideias, propor e discutir soluçóes são meios de participação que podem ser livremente intercambiados entre os agentes, sem que se restrinja qualquer deles a qualquer agente único.

\section{Redes horizontais: uma tendência}

Não é só na arquitetura e no urbanismo que se identifica a necessidade de horizontalizar os processos de produção. Em Future Perfect (2012), Steven Johnson identifica várias instâncias em que se começa a perceber uma tendência de organização no que ele chama de peer networks. Um dos exemplos é o das malhas ferroviárias da França e da Alemanha. Enquanto a da França foi constituída no modelo que ficou conhecido como "Estrela de Legrand", pelo seu formato radial com Paris no centro, a da Alemanha tinha formato de rede com nós sem hierarquia definida. O modelo francês tinha algumas vantagens: as linhas a partir de Paris eram retas e o comprimento total da rede era relativamente menor, permitindo investimento em trens e linha mais rápidas e eficientes. Também permitiu o rápido acesso de Paris, a maior cidade e centro do poder, ao resto do país. Mas quando estourou a guerra Franco-Prussiana de 1870, as vantagens se anularam: as tropas de Bismarck tinham diversos caminhos para se deslocar até o front de batalha, enquanto toda a circulação francesa dependia de Paris.

A centralização pode ser justificada em aspectos e escalas muito específicas, como no caso da Estrela de Legrand; mas, no longo prazo, o desenvolvimento abrangente é incompatível com uma estrutura centralizada. A dependência do nó central começa a se tornar um entrave na medida em que a rede se torna mais complexa. A escala da cidade talvez seja o melhor exemplo disso. O diagnóstico já aparece em um texto de John Friedmann de 1973: "The barriers to effective communication between those who have access primarily to processed knowledge and those whose knowledge rests chiefly on personal experience are rising. (...) The real solution involves a restructuring of the basic relationship between planner and client. (...) Although personal knowledge is much richer in content and in its ability to differentiate among the minutiae of daily life, it is less systematized and orderly than processed knowledge." (Friedmann, 2011)

A própria distinção entre "conhecimento processado" e "conhecimento pessoal" é evidência do problema: em qualquer entidade autônoma o conhecimento processado, ou seja, aquele que é organizado para resultar em ação, é o mesmo que o pessoal. Se há uma distinção, é porque as informações que balizam as ações de desenvolvimento urbano são distintas das que são relevantes para o cidadão comum. Dois problemas decorrem desta lógica: primeiro, uma grande quantidade de tempo e recursos são alocados para extrair e produzir o conhecimento processado, através de estudos, diagnósticos, pesquisas e equipamentos; além disso, todo o conhecimento real - aquele vivenciado pelas pessoas, que a produção do conhecimento "processado" tenta emular - é jogado fora, perdido em queixas entre vizinhos que não cumprem propósito maior do que os distrair enquanto esperam o elevador. A questão, então, não é como desenvolver métodos de reproduzir sistematicamente a experiência popular para depois, conscientemente, transformá-la em políticas públicas, em um processo que costuma demorar anos e se perder no caminho. É uma questão de criar instituiçôes e ferramentas que permitam que o ciclo entre conhecimento popular e ação ocorra não em anos, mas em dias, horas - ou instantaneamente.

\section{As Lições da Tecnologia}

Os Sistemas Operacionais se popularizaram na década de 1980 com a criação dos computadores pessoais. A Apple e a Microsoft gastaram e ainda gastam fortunas para desenvolver os sistemas que as transformaram em gigantes da indústria. Em 1991 o finlandês Linus Torvalds lançou o primeiro sistema operacional com códigofonte aberto: o Linux. Durante anos seu uso e desenvolvimento se restringiu a pequenos grupos de estudantes e profissionais com avançado conhecimento técnico, não se comparando, em número de usuários, com os sistemas proprietários das duas gigantes americanas; com a popularização da World Wide Web e o desenvolvimento de dispositivos computacionais variados, como aparelhos celulares, tablets, centrais multimídia e dispositivos de automação residencial, entre tantos outros, sua popularidade cresceu exponencialmente. A complexidade de um sistema operacional justifica que se adote algum tipo de padrão, já que é necessário ter massa crítica capaz de desenvolvê-lo através da mesma linguagem; mas, por mais que contem com batalhóes de desenvolvedores, as gigantes Apple e Microsoft não conseguem - ou não justificam comercialmente investir na adaptação de seus sistemas a cada demanda específica. Por este motivo, o Linux é, desde 2011, o sistema operacional mais usado no mundo, em número de aparelhos (Tu, 2012). Apple e Microsoft ainda dominam o campo dos PCs, que são uma plataforma homogênea baseada em uma linha fornecimento de peças bastante consolidada; em quase todas as outras áreas, no entanto, o Linux domina. É usado em mais de $80 \%$ dos smartphones e em 482 dos 500 computadores mais rápidos do mundo e (VaughanNichols, 2013), além de vastamente usado em videogames, servidores, sensores e outros dispositivos que demandam algum nível de customização do sistema. 
Outro exemplo que vem da tecnologia da informaçáo é o Waze. Nos últimos anos os dispositivos de navegação para carro com localização por GPS se popularizaram. Algumas empresas surgiram e prosperaram vendendo equipamentos e mapas para alimentá-los, oferecendo também atualizaçôes periódicas. Empresas como a TomTom começaram a oferecer, além dos mapas, informaçóes sobre o trânsito que eram transmitidas diretamente para o aparelho por meio de ondas de rádio FM, mediante pagamento anual. A popularizaçáo dos sensores de GPS em aparelhos celulares, no entanto, tem afetado essas empresas. As ações da TomTom perderam mais de $90 \%$ do seu valor nos últimos 7 anos ("TomTom NV (TOM2.AS) Financial Charts," 2014). Estas empresas perderam espaço para aplicativos baseados em crowdsourcing como o Waze, fundado em 2008. Na maioria das regiôes em que atua, o Waze não investe em levantamento e manutenção de dados. Quando chega em uma rua não cadastrada, o usuário pode fazer seu levantamento pelo seu aparelho celular e depois editar, pelo site, informaçóes como o nome da rua, fluxo do tráfego, conversões proibidas e números dos imóveis. Outros usuários podem escrutinar e detalhar as informaçóes. Uma vez cadastrada, informaçóes como a velocidade do trânsito e a ocorrência de eventos (acidentes, obras etc.) são registradas automaticamente. Com base nestas informações, o aplicativo pode sugerir rotas aos usuários que levem em conta informaçóes em tempo real e indiquem o caminho mais rápido. $\mathrm{O}$ mérito do Waze não é criar e manter informações relevantes atualizadas, mas fornecer a plataforma para que os usuários o façam. Em regióes com poucos usuários empresas como a Tom Tom ainda se justificam; na medida em que o número de usuários cresce, no entanto, elas vão se tornando incapazes de atualizar manualmente os dados que, em aplicativos baseados em crowdsourcing, são extraídas de forma automática e atualizadas instantaneamente. A recursividade do fluxo de informaçóes é clara: ao mesmo tempo em que obtém do servidor informaçóes atualizadas sobre o estado do trânsito, o usuário envia dados sobre as rotas que está tomando. Mesmo que não envie manualmente qualquer informação, como quando relata um acidente, e que não aprimore os mapas através da edição online, o usuário está enviando dados sobre a velocidade do trânsito. Desta forma, cada pessoa participa da plataforma em algum nível, e ninguém é apenas usuário - da mesma forma que ninguém é apenas editor. A empresa Waze permanece privada e o código-fonte do programa é de sua propriedade, o que mantém a "caixa preta" do aplicativo pelo menos parcialmente fechada; mas sua relevância está na quantidade de usuários e na capacidade de criar uma plataforma que sirva de interface entre esses usuários e a infraestrutura viária.

\section{A Cidade Aberta}

A analogia entre plataformas tecnológicas e cidade é oportuna. Talvez a centralização do planejamento se justifique ao longo dos Séculos XIX e XX, considerando a necessidade de desenvolvimento de algumas soluçóes planejadas e únicas, como os sistemas de esgoto decorrentes das pesquisas de John Snow na Londres do Século XIX. Da mesma forma que Microsoft e Apple foram importantes no desenvolvimento de sistemas operacionais, ou que a TomTom contribuiu para o uso difundido de aparelhos de navegação veicular. Mas a tendência de transição para sistemas menos centralizados que é verificada nestes outros campos é, na cidade, ainda muito tímida. Ainda que algumas tentativas tenham sido feitas para abrir o planejamento urbano à população, por meio, por exemplo, do Orçamento Participativo, o desenvolvimento das cidades continua sendo produto do trabalho executado dentro de caixas pretas, fechadas pelos governos municipais e pelo corpo técnico das administraçóes públicas.

A maioria das cidades ocidentais é hoje planejada dentro da matriz do planejamento Euclidiano, em que mapas coloridos determinam o zoneamento de cada lote e, com isso, quais tipos de ocupaçóes e usos são permitidos em cada um. $\mathrm{O}$ reconhecimento da complexidade das cidades resultou na multiplicação do número de cores em cada mapa, além de mapas que se sobrepóem e uma infinidade de parâmetros cada vez mais complexos e aparentemente arbitrários. É difícil contestar o valor deste tipo de planejamento em seu contexto histórico; mas é igualmente difícil imaginar que a mesma lógica geral desenvolvida nos EUA há mais de um século seja capaz de balizar o desenvolvimento urbano de milhares de cidades com Planos Diretores inspirados, predominantemente, na mesma lógica - independente das peculiaridades de cada cidade e de cada população.

No momento em que o desenvolvimento das cidades deixou de depender exclusivamente das atitudes construtivas diretas e náo reguladas dos seus cidadáos, iniciou-se uma ruptura entre a obtenção de conhecimento (diagnóstico) e a colocação em prática deste conhecimento com fins de planejamento. Qualquer que seja a forma de planejamento adotada, há sempre uma lógica de obtenção e análise de dados que dá origem às definiçôes de planejamento que balizarão o desenvolvimento urbano. Essa lógica é, via de regra, uma simplificação que, ainda que justificada pelo arcabouço tecnológico e político dominante, alija o povo da definição dos rumos da cidade. A disponibilidade de informação e a tecnologia de que dispomos atualmente permitem que se caminhe em direçáo à reversão desta tendência.

A qualidade da experiência urbana de cada cidadão depende de uma infinidade de fatores que são, de alguma forma, intercambiáveis entre si: cada cidadão toma, constantemente, uma série de decisôes baseadas em sua percepção da equivalência entre elas: "vou de ônibus ou a pé?”, por exemplo, é uma pergunta cuja resposta depende do custo das tarifas, do clima, da qualidade dos passeios, da distância a ser percorrida, da qualidade do ar e do ambiente urbano, entre tantos outros fatores. A soma dessas escolhas tem consequência na produção do espaço urbano, mas por um viés quase estritamente financeiro. A parcela dessa gama de elementos que envolvem a decisão só tem impacto na produção da cidade pela escolha de pagar ou não a tarifa do ônibus. Todos os demais elementos são diluídos e condensados em uma percepção espacial subjetiva e muito pessoal do indivíduo que não resulta na produçáo efetiva do espaço. Os cidadãos crescem com a percepção de que influenciam cada vez menos o desenvolvimento espacial da cidade. Se náo há uma instituição pública e "participativa” envolvida, o cidadão comum 
só influencia a produção do espaço urbano de forma espontânea quando há uma relação de consumo.

Não precisa ser assim. Ao obter, organizar e disponibilizar dados dos diferentes aspectos da vida urbana e sistematizar as equivalências que as pessoas fazem o tempo todo, é possível que a definição da criaçâo de um parque ou de uma escola, por exemplo, possa ser balizada por mais do que a planilha de custos de implantação e das receitas com a potencial valorização imobiliária da região. Ou seja, as decisóes urbanas podem acontecer por meio de plataformas abertas em que os cidadãos troquem ideias e propostas sem a necessidade de mediação institucional ou financeira.

A analogia com sistemas abertos mostra que quanto mais as experiências e ideias individuais dos cidadãos (usuários) encontram caminho para a forma como a cidade (o sistema) se desenvolve, mais bem aproveitados e justamente distribuídos os diferentes capitais urbanos, e menor a lacuna entre a cidade real e a cidade planejada. Quanto maior a autonomia que o planejamento urbano possibilita aos cidadãos, mais adequada a produção e manutenção do espaço urbano por parte de quem o faz e ocupa.

A soma das inteligências individuais só resulta em uma atuação coletiva inteligente se os indivíduos possuem um meio através do qual interagir de forma qualificada. Abrir o código-fonte da cidade permitirá chamar todos os cidadáos para que o façam de forma direta, sem a intermediação necessária dos sistemas político-financeiros.

Se o planejamento urbano ocidental está em crise, não são mais urbanistas ainda mais especializados que conseguirão, individualmente, promover alguma mudança. O sucesso do Linux decorre de sua capacidade de adaptação independente de um gerenciamento central. Tanto as cidades quanto seus cidadãos demandam o mesmo tipo de liberdade. É possível desenvolver interfaces, a exemplo da experiência do Waze, que permitem que nenhum usuário se situe nos extremos entre a vida ativa e a vida contemplativa: ninguém precisa ser individualmente responsável por planejar tudo e ninguém deve ser mero agente passivo da cidade, cada um informando e se informando na medida de suas capacidades e demandas. O caminho para o paradigma erótico não é inevitável: não vai acontecer instantaneamente, porque durante geraçóes aprendemos que certos aspectos da vida em sociedade, como as cidades, nos sáo dados de forma pronta. Mas é desejável: as plataformas colaborativas já são realidade em diversos campos. Na cidade - talvez a mais importante plataforma colaborativa da humanidade - a grande informalidade e a complexidade da legislação que não resulta em qualidade urbana são provas da necessidade de criaçáo destas interfaces. $\mathrm{O}$ papel do planejamento urbano é, mais do que desenvolver fórmulas precisas para cada pedaço da cidade, criar plataformas para permitir que as boas ideias dos milhóes de habitantes das cidades parem de morrer em conversas de elevador.

\section{Referências}

Baltazar, A. P. (2013). A Sedução da Imagem na Arquitetura: Metaramoris como alternativa pós-histórica. In R. Duarte (Ed.), Imagem, Imaginação, Fantasia: 20 anos sem Vilém Flusser.

Demographia. (2013). Demographia World Urban Areas World Agglomerations (9th Annual Edition ed.). Belleville.

Descartes, R. (1967). Le Discours de la Méthode. Paris,: L. Mazenod.

Friedmann, J. (2011). Insurgencies : essays in planning theory. Abingdon, Oxon ; New York, NY: Routledge.

Jacobs, J. (1961). The death and life of great American cities. New York: Random House.

Johnson, S. (2006). The ghost map : the story of London's most terrifying epidemic--and how it changed science, cities, and the modern world. New York: Riverhead Books.

Johnson, S. (2012). Future perfect: the case for progress in a networked age. New York: Riverhead Books.

Kapp, S., \& Baltazar, A. P. (2012). The Paradox of Participation: A Case Study on Urban Planning in Favelas and a Plea for Autonomy. Bulletin of Latin American Research, 31(2), 160173. doi: $10.2307 / 41410613$

TomTom NV (TOM2.AS) Financial Charts. (2014). Retrieved 01/02/2014, 2014, from http://www.reuters.com/finance/ stocks/chart?symbol=TOM2.AS

Tu, J. I. (2012). Goldman Sachs: Microsoft has gone from 97 percent share of compute market to 20 percent. Retrieved 01/02/2014, 2014, from http://seattletimes.com/html/microsoftpri0/2019853243_goldman_sachs_microsoft_os_has_ gone_from_more_than.html

Vaughan-Nichols, S. J. (2013). Where Linux rules: Supercomputers: ZDNet. 